\title{
Construction of ecological model for development of small and micro enterprise informatization
}

\author{
Rongna Geng ${ }^{1,}$, , Suchun Fang ${ }^{2, b}$ \\ ${ }^{1}$ Chanchun University of Technology, china \\ ${ }^{2}$ SEISEN University, Japan \\ aquingrn2006@126.com, ${ }^{b}$ fang-s@seisen.ac.jp
}

\begin{abstract}
Keywords: small and micro enterprise; informationization; information ecology; information ecosystem.

Abstract. Informationization is the trend of economic and social development. Small and micro enterprise informationization can not only integrate modern information technology, advanced management concepts and management technology, but also reintegrate internal and external resources of enterprises' in order to improve enterprise efficiency and enhance enterprise competitiveness. From the perspective of information ecology, this paper analyzes the performance of the ecological imbalance of small and micro enterprises in our country, and constructs the healthy information ecosystem of small and micro enterprises.
\end{abstract}

\section{Introduction}

In recent years, the number and scale of small and micro enterprises gradually increased; however, the global economy and the development of domestic market have brought unprecedented pressure to survive for small and micro enterprises. So many small and micro enterprises are eager to improve enterprise efficiency, reduce costs and enhance competitiveness by information. Good information ecological environment is the key to the informationization of small and micro enterprises.

The content of information ecology environment. Information environment is the sum of all the elements of information exchanges and information activities around the human and social organization. Information ecological environment is the environment that it is constructed by the information resources and the influence factors of the specific information exchange activities in the information ecosystem. The difference between the two is that the information ecology environment is more focused on the ecology. The information ecology environment of small and micro enterprises refers to the environment in which the information components and non information components interact through consuming information products and providing information services. Ultimately the information needs of information body can be meet.

The elements of information ecological environment of small and micro enterprises mainly include: political environment, technology environment, human environment and economic environment. In the political environment, policy and law are the main factors ; In the cultural environment, the concept of value, education level of enterprise employees and social culture and customs are the main factors ; In the economic environment, the national economic macro environment and information economy policy are the main factors ; In the technology environment, the application and transformation of technology are the main factors.

The present situation of small and micro enterprise information ecosystem environment. At present, the domestic enterprises take the customers as the center, moreover, they put product development, production, marketing and after-sales service and others together into the information economy environment through the network media. According to the national data statistics, Chinese small and medium enterprises accounted for $99.7 \%$ of the total number of enterprises, of which small and micro enterprises accounted for $97.3 \%$, while the proportion of the informationization is less than 
10\%.[1] Obviously, small and micro enterprise information environment is particularly weak. In the process of information construction and management of small and micro enterprises, the main problems of information ecology environment are as follows. [2]

The imbalance of small and micro enterprise information development level. As "vulnerable groups" in Chinese economic and ecological system, small and micro enterprises which have implemented the informationization are less and less. Even if some small and micro enterprises have implemented the informationization, the results are only superficial. Due to the lack of information support, the majority of small and micro enterprises' management are in an extensive, chaotic state. Different small and micro enterprise information development is not balanced mainly in the type of business, industry and the regional economic situation and other aspects. From the view of enterprise type, export-oriented enterprises, scientific and technological enterprises, and small and micro enterprise associated highly with large enterprises develop quickly in information building, while the small and micro enterprises with weak competitiveness and poor efficiency as well as small and micro enterprises in villages and towns develop more slowly in information building. From the view of industry type, the industries with high technology content and traditional competitive advantage have high popularity in information development, such as electronics, export, processing and manufacturing, high-tech, real estate, textile and other industries. In addition, enterprise information development level is better in the region with high economic development level and the high marketization degree. The imbalance of small and micro enterprises information development level has seriously affected the overall balance of small and micro enterprise information ecosystem, furthermore, it is not conducive to the overall information superiority.

The imbalance exists in management idea and information technology. The small and micro enterprises which have realized informationization still remain at the stage of technological determinism about the construction of information. Information is not equal to the accounting machine, this point in the large enterprises has reached a consensus, and many small and micro enterprises is still not clear. The construction and management of small and micro enterprise information are mostly in the scope of information technology, but with the rapid development of information technology, technical barriers are becoming smaller and smaller. A lot of factors that influence the construction and management of the enterprise information not belong to the technical aspects, including the enterprise business process specification, enterprise information planning, corporate leadership support, etc. These are reflection of enterprise information environment and belong to management idea scope. Backward management ideas and advanced information technology can not adapt, which have greatly weakened the economic benefits of informationization. Therefore, the imbalance exists in management idea and information technology is the main factor that affects the information ecology balance of small and micro enterprises.

The imbalance of information construction. The structure of many small and micro enterprises information construction is irrational. Such tendency and misunderstanding are existed in the small and micro enterprise, that is to pay attention to the construction but neglect the needs, pay attention to investment but neglect maintenance, pay attention to introduction but neglect application, pay attention to hardware but neglect software, pay attention to network but neglect resources. Usually, small and micro enterprises have established sites are only to release information. The electronic commerce enterprise is little and little. Therefore, the imbalance of the information structure has caused the local imbalance of the information ecology of small and micro enterprises.

The imbalance exists in information needs and information talents. Small and micro enterprise informationization is a long process, which needs a group of professionals to build, operate, maintain and update. But in fact, most of the small and micro enterprises have no special information department, or the information sector technology is weak, or the level of information technology personnel is not high or the number of personnel is not enough, especially the inter-disciplinary talents who know not only technology but also management are less. Therefore, the lack of professional 
information talents is a key factor which has affected the imbalance of information ecosystem of small and micro enterprises.

The Construction of benign information ecosystem for small and micro enterprise. Small and micro enterprise informationization can not be solved through a set of software, a website or a solution. Rapid changing market environment is not conducive to the recovery of the information input and the embodiment of benefit. The smooth development of small and micro enterprises informationization not only need enterprise's own efforts, but also should consider the social information service environment. Therefore, the construction of small and micro enterprise information ecosystem can gradually realize the information of small and micro enterprises.

The culturing of excellent key species. Information ecosystem is composed of three factors, which are information, human and information technology. Human is the main factor among them, which is responsible for the exchange and transmission of information. Information technology is an important factor, which is the basic tool for creating, collecting, storing, transmitting and utilizing information resources. Information is the carrier, who is to achieve the needs' change and transmission which happened in people and information technology; moreover, it can realize the collaborative growth of ecological system. In small and micro enterprise information ecosystem, there are three main kinds of "species", that is, small and micro enterprises, government and related management mechanism, financial and other services. These three kinds of main body in the information ecology system carry on the information production, the transmission, the processing and so on. They are important factors that affect the cooperative development of information ecosystem. [3]

The full using of small and micro enterprise media species. Information ecology system, as well as biological ecology, is composed of various components, and each part is connected with each other. To meet the information needs of small and micro enterprises, information ecosystem needs to include a large number of information media species. There are three main categories: Business media species. Some e-commerce platform accumulate a large number of transaction data when they participate in the business activities of small and micro enterprises, in turn, they can use the data as a basis to provide value-added services for small and micro enterprises. These data were obtained through business media are more real than the financial data what small and micro enterprise have, furthermore, which have great social and economic values. Software media species. The species provide information software and information solutions for the small and micro enterprises. The species use their own rich engineering experience to provide personalized software and solution for small and micro enterprise informationization. Data media species. The species not only obtain information from public websites but also provide data and related services through data mining.

The application of technology in management. The application of information technology in small and micro enterprises should not only focus on the business process of information technology but also concentrate in the enterprise system construction, business process optimization, and organizational structure change and so on. These aspects must be closely cooperated with information technology to promote each other. According to the analysis of the existing research, the information technology and realization means of small and micro enterprise in information ecosystem mainly focus on three aspects, that is, the own internal information technology of small and micro enterprises, the information technology which exists between small and micro enterprises and government management department; the information technology which exists among financial institution and other service agencies and small and micro enterprises.

The collaborative evolution of different species. Information ecosystem of small and micro enterprises is composed of information producers, information transmitter, information consumers and information decomposer. The four information bodies interact and influence each other. Any change of one information body will affect other information body to make the corresponding change. Thus, small and micro enterprises should focus on the evolution of some specie to promote the collaborative evolution of the whole species.

The creation of efficient information ecology service environment. The construction of information ecological environment of small and micro enterprise includes internal environment and 
external environment. Internal construction should take into account the organizational environment, the quality of personnel, and the interaction between people and information systems. External construction should have good political, economic, cultural, legal and other external environment support.

The establishment of information ecology circle of small and micro enterprises. The information ecology circle not only provides multi levels information but also provides standard management and solution. Information and services provided by the ecology circle can help enterprises to reduce resource consumption and wasting, which has ecological environmental protection features. The function and structure of information ecology circle are composed of the information age, information cycle chain and ecological circle balance. The information cycle in small and micro enterprise information ecosystem has an important economic and commercial significance. It has the role of communication between various enterprises and their upstream and downstream enterprises, survival development environment and the consumer. Each small and micro enterprise can be regarded as a small information ecosystem, which has its own unique content. Each industry's small information ecosystem constitutes a large information ecological circle; simultaneously they interact, restrict and merge each other. The information ecology circle has the multi type information, fast information circulation and powerful system adjustment function, so that the small and micro enterprises can obtain the full range of information. Finally the balance between supply and demand can be quickly reached. [4, 5]

\section{Conclusions}

This paper analyzes the four performances of the information ecology imbalance of small and micro enterprises.

The construction of small and micro enterprise information ecosystem needs to create three key species. They evolve collaboratively through a clear division of labor.

Building a good information ecosystem of small and micro enterprise will promote the development of small and micro enterprise informationization.

\section{References}

[1] Guifang Jiao. Research and Analysis on the development of small and micro enterprises [J]. Management space, 2012, 4:133.In Chinese

[2] Bo Shi. Countermeasures for improving the information ecosystem of small and medium enterprises [J]. Management \& Technolosy of SME, 2010.2.In Chinese

[3] Yan Li, Ping Zhao. Research on the review and implementation of the small and micro enterprise information [J]. Theory Horizon, 2014.1.In Chinese

[4] Xukan Xu, Yijie Bian. Research on the environment maturity of enterprise information ecosystem [J]. Information Science, 2011, 29(2):207-210. In Chinese

[5] Xukan Xu, Xiaodong Li. Growth model Construction of enterprise information system based on ecological theory [J]. Journal of Intelligence, 2009, 28(9):17- 20.In Chinese 